\title{
Iridoid and phenylethanoid glycoside production and phenotypical changes in plants regenerated from hairy roots of Rehmannia glutinosa Libosch.
}

\author{
Ewelina Piątczak • Lukasz Kuźma • \\ Ewa Skała $\cdot$ Marta Żebrowska $\cdot$ Ewa Balcerczak • \\ Halina Wysokińska
}

Received: 29 October 2014/ Accepted: 25 January 2015/Published online: 4 February 2015

(C) The Author(s) 2015. This article is published with open access at Springerlink.com

\begin{abstract}
Spontaneous shoot regeneration was obtained from the hairy roots of Rehmannia glutinosa cultured in liquid woody plant medium for 4 weeks in darkness after induction by Agrobacterium rhizogenes strain A4. These shoots were proliferated on solid Murashige and Skoog (MS) medium in $300 \mathrm{~mL}$ glass jars and in liquid MS medium in a $5 \mathrm{~L}$ nutrient sprinkle bioreactor. These media were supplemented with $0.1 \mathrm{mg} \mathrm{L}^{-1}$ of indole-3-acetic acid (IAA) and $1.0 \mathrm{mg} \mathrm{L}^{-1}$ of 6-benzylaminopurine. All shoots became rooted on MS agar medium containing IAA or indole-3-butyric acid within 4 weeks. The plantlets were then transferred into soil and grew in a greenhouse. The transgenic nature of the plants was confirmed by polymerase chain reaction (PCR) and reverse-transcriptase PCR analyses. The pRi-regenerated transformants demonstrated a few phenotypical alterations. Production of six iridoid (catalpol, aucubin, loganin, catalposide, harpagide, harpagoside) and two phenylethanoid (verbascoside and isoverbascoside) glycosides was determined in shoots cultured in vitro and leaves and roots of 6- and 12-month-old plants by ultra high performance liquid chromatography. The shoot culture was able to synthesize low amounts of
\end{abstract}

Electronic supplementary material The online version of this article (doi:10.1007/s11240-015-0727-1) contains supplementary material, which is available to authorized users.

E. Piątczak $(\varangle) \cdot$ Ł. Kuźma · E. Skała $\cdot$ H. Wysokińska

Department of Biology and Pharmaceutical Botany, Medical

University of Łódź, Muszyńskiego 1, 90-151 Lodz, Poland

e-mail: ewelina.piatczak@umed.lodz.pl

\section{M. Żebrowska - E. Balcerczak}

Laboratory of Molecular Diagnostic and Pharmacogenomics, Department of Pharmaceutical Biochemistry and Molecular Diagnostic, Medical University of Łódź, Muszyńskiego 1, 90-151 Lodz, Poland catalpol, verbascoside and isoverbascoside. Leaves and roots of pRi-regenerants accumulated similar (harpagoside, isoverbascoside), higher (catalposide, aucubin, harpagide, verbascoside) or lower (catalpol, loganin) levels of the metabolites in comparison with untransformed $R$. glutinosa plants and their content varied with the age of the plants and the organ analyzed. However, the increase in shoot and root biomass of transformed plants resulted in a significantly greater yield of all analyzed compounds.

Keywords Agrobacterium rhizogenes · Iridoid glycosides · Phenylethanoid glycosides - Rehmannia glutinosa . Transformed plants

\begin{tabular}{ll}
\multicolumn{2}{l}{ Abbreviations } \\
BAP & 6-Benzylaminopurine \\
DW & Dry weight \\
FW & Fresh weight \\
HR-plants & Hairy root-derived plants \\
HR-shoots & Hairy root-derived shoots \\
IAA & Indole-3-acetic acid \\
IBA & Indole-3-butyric acid \\
MS & $\begin{array}{l}\text { Murashige and Skoog medium (Murashige } \\
\text { and Skoog 1962) }\end{array}$ \\
SD-plants & Seed-derived plants \\
SE & Standard error
\end{tabular}

\section{Introduction}

Rehmannia glutinosa Libosch. (Orobanchaceae) (APG III 2009) is a valuable medicinal perennial occurring naturally in China, Japan and Korea, which is regarded as one of the 
50 fundamental herbs in Traditional Chinese Medicine. Rehmanniae radix (Di Huang) is ranked as an "upper grade" medicine in the Chinese pharmaceutical classic Shen-Nung's Pen-Ts'so (Kitagawa et al. 1991). These roots are widely used as antianemic, antipyretic, antisenescence, antitumor and hypoglycemic agents (Kitagawa et al. 1991; Zhang et al. 2008). The pharmacological properties of the roots have been attributed mainly to the presence of iridoid (catalpol, aucubin) and phenylethanoid (verbascoside, isoverbascoside, echinacoside) glycosides.

Our previous paper has described the establishment of hairy root cultures of $R$. glutinosa and production of iridoid (catalposide, loganin, catalpol and aucubin) and phenylethanoid (verbascoside and isoverbascoside) glycosides in ten hairy root lines transformed with Agrobacterium rhizogenes strain A4 (Piątczak et al. 2012). These hairy root lines exhibited differences in secondary metabolite contents. In high-producing lines, the levels of catalposide, verbascoside and isoverbascoside were several times higher than those seen in untransformed root culture and the roots of field-grown $R$. glutinosa plants (Piatczak et al. 2012). Further improvement in the metabolite production could be provided by the regeneration of whole plants from high-producing hairy root lines. According to Christey (2001) transgenic plants have been obtained after A. rhizogenes-mediated transformation of 89 different taxa, representing more than 79 plant species, and more transformed plant taxa, e.g. Plumbago indica (Gangopadhyay et al. 2010) or Tylophora indica (Chaudhuri et al. 2006) demonstrate higher level of secondary metabolites than untransformed plants.

Plants regenerated from hairy roots are generally nonchimera since each hairy root line originates from a single cell (Bercetche et al. 1987). However, they often exhibits various types of phenotypical alterations such as wrinkled leaves, shortened internodes, increase lateral branching, reduced apical dominance and better root yield than untransformed plants, which has been attributed to the fact that T-DNA from the bacterial Ri plasmid is transferred into infected plant cells and becomes stably integrated into the plant genome (Giri and Narasu 2000).

Transformation of R. glutinosa by A. rhizogenes (strain 15834 ) has already been investigated with regard to possibility of plant regeneration, their morphology and catalpol production (Hwang 2005). However, no data is available concerning the production of other bioactive secondary metabolites in transformed $R$. glutinosa plants.

The present paper describes an efficient system for the regeneration of $R$. glutinosa plants from a high-producing hairy root line transformed with $A$. rhizogenes A4 strain. It describes the changes in the morphology of regenerated plants growing under greenhouse conditions. UHPLC was used to investigate the production of iridoids (catalpol, aucubin, loganin, catalposide, harpagide, harpagoside) and phenylethanoids (verbascoside, isoverbascoside) in proliferating transformed shoot cultures and transgenic plants with regard to their organ (leaves and roots) and age (6and 12-months old). The findings are compared to the production of these compounds in the leaves and roots of 12-month-old untransformed $R$. glutinosa plants derived from seeds.

\section{Materials and methods}

\section{Plant material}

Rehmannia glutinosa Libosch. hairy root line (RS-2) induced by A. rhizogenes strain A4 was used as the starting material. The hairy roots were cultured in $300 \mathrm{~mL}$ Erlenmeyer flasks containing $80 \mathrm{~mL}$ of WPM liquid medium and grown in the dark at $26 \pm 2{ }^{\circ} \mathrm{C}$ (Piątczak et al. 2012).

\section{Shoot regeneration and multiplication}

Shoots (named HR-shoots) spontaneously formed on the hairy root surface were excised and transferred into agar $(0.7 \%$ w/v SIGMA, Aldrich) solidified MS medium supplemented with $0.1 \mathrm{mg} \mathrm{L}^{-1}$ IAA and $1.0 \mathrm{mg} \mathrm{L}^{-1}$ BAP and sucrose $(3 \% \mathrm{w} / \mathrm{v})$ hereafter referred as shoot multiplication medium. The culture was maintained in a growth chamber under light (PPFD $40 \mu \mathrm{mol} \mathrm{m} \mathrm{m}^{-2} \mathrm{~s}^{-1}$ fluorescent light lamps; photoperiod $16 \mathrm{~h}$ light $/ 8 \mathrm{~h}$ dark) at $26 \pm 2{ }^{\circ} \mathrm{C}$. The incubation conditions were maintained throughout the whole study. The shoots were subcultured for 10-12 subcultures at 4-week intervals, until they formed stable shoot culture. For further shoot proliferation two different culture systems were used. The first used individual shoot tip explants cultured on $50 \mathrm{~mL}$ of solid shoot multiplication medium in $300 \mathrm{~mL}$ glass cap jars: the average fresh weight (FW) of inoculum was $0.05 \mathrm{~g} \pm 0.001$ and the average dry weight (DW) was $0.003 \mathrm{~g} \pm 0.0005$. In the second, a mean number of seventeen HR-shoot tips (3-5 $\mathrm{mm}$ long) were placed into a $5 \mathrm{~L}$ sprinkle bioreactor containing liquid shoot multiplication medium $(1 \mathrm{~L})$. The bioreactor specifications have been described previously (Piątczak et al. 2014). The circulation rate of the medium was $60 \mathrm{~mL}$ per each $40 \mathrm{~s}$ delivery, with $3.0 \mathrm{~min}$ breaks between each delivery. For the experiment inoculum of average FW $0.3 \mathrm{~g} \pm 0.001$ and average DW $0.018 \pm 0.009$ was taken.

After 4 weeks of culture in the glass jars and the bioreactor the multiplication rate, i.e. the number of harvested shoots/number of explants, and the average FW and DW expressed as g per liter were recorded. HR-shoot multiplication experiments were repeated three times in three independent experiments (three bioreactor runs or 
three subsequent subcultures, each consisting of three jars). The results were presented in Table 1 as mean \pm standard error (SE).

Rooting and acclimatization of regenerants

For rooting, the 4-week-old HR-shoots multiplied in the bioreactor were transferred individually into glass tubes containing $25 \mathrm{~mL}$ of MS agar-solidified medium without growth regulators or supplemented with IAA or IBA at a concentration $0.1 \mathrm{mg} \mathrm{L}^{-1}$. After 4 weeks, the percentage of rooted shoots, length of roots $(\mathrm{mm})$ and average number of roots per shoot were recorded. The rooting experiments were repeated three times. A total of 30-45 shoots were used for each rooting medium variant: MS medium without plant growth regulators or supplemented with IAA or IBA $\left(0.1 \mathrm{mg} \mathrm{L}^{-1}\right)$. The rooted shoots were washed in tap water to remove agar from the roots and transferred into pots $(\varnothing$ $10 \mathrm{~cm}$ ) as described previously (Piątczak et al. 2014). The experiments were repeated three times with $10-15$ plants cultivated each time, giving a total of 40 plantlets transferred into pots. The survival rates of the plants were recorded after 8 weeks of growth in the pots in the greenhouse under controlled temperature and natural light. Plants obtained from hairy roots were named HR-plants. Untransformed $R$. glutinosa plants were obtained from seeds from the Garden of Medicinal Plants, Medical University of Wrocław and grown in the greenhouse under identical conditions as transformed plants. The plants were named SD-plants and served as controls.

After 1 year, data on the average number of leaves per plant, the average number of lateral branches and the average length and width of a single leaf $(\mathrm{cm})$ as well as

Table 1 Growth of $R$. glutinosa transformed shoots in glass cap jars on solid MS medium and in a nutrient sprinkle bioreactor in liquid MS medium for 4 weeks. Media were supplemented with IAA $\left(0.1 \mathrm{mg} \mathrm{L}^{-1}\right)$ and $\operatorname{BAP}\left(1.0 \mathrm{mg} \mathrm{L}^{-1}\right)$

\begin{tabular}{lrr}
\hline Parameter & \multicolumn{2}{c}{ Shoots multiplied in } \\
\cline { 2 - 3 } & \multicolumn{1}{c}{ Glass jars $^{\mathrm{a}}$} & \multicolumn{1}{c}{ Nutrient sprinkle bioreactor $^{\mathrm{b}}$} \\
\hline Shoot biomass $\left(\mathrm{g} \mathrm{L}^{-1}\right)$ & \\
FW & $33.80 \pm 1.50$ & $70.35 \pm 1.66$ \\
DW & $2.9 \pm 0.10$ & $6.45 \pm 0.17$ \\
Multiplication rate & $17.05 \pm 1.55$ & $28.00 \pm 1.16$ \\
\hline
\end{tabular}

${ }^{\text {a }}$ Shoots were multiplied in $300 \mathrm{~mL}$ glass jars containing $50 \mathrm{~mL}$ of solid medium

b Shoots were multiplied in $5 \mathrm{~L}$ bioreactor containing $1 \mathrm{~L}$ of liquid medium

The data are the mean of three independent experiments (three subsequent subcultures in glass jars or three bioreactor runs) $\pm \mathrm{SE}$ the average fresh and dry weights of roots and shoots per plant were calculated for the HR- and SD-plants. The results presented in Table 2 are the means of 20 HR-plants and 20 SD-plants \pm SE and they were analyzed by MannWhitney $\mathrm{U}$ test at $p \leq 0.05$.

\section{Molecular identification of HR-plants}

\section{DNA extraction and PCR analysis}

Nucleospin Plant II Kit (Macherey-Nagel, Germany) was used to isolate genomic DNA from fresh leaves taken from 10 randomly selected 12-month-old HR-plants grown in pots in the greenhouse. The leaves from single 12 monthold SD-plant were used as control material. The plant material $(200 \mathrm{mg})$ was powdered in liquid nitrogen and stored at $-80{ }^{\circ} \mathrm{C}$ until extraction. Polymerase chain reaction (PCR) was performed by using each DNA sample as template to test the presence of the rolA, rolB and rolC genes in the T-DNA. Plasmid DNA isolated from A. rhizogenes cells (strain A4) was used as a positive control. The bacteria containing Ri-plasmids were grown overnight at $37^{\circ} \mathrm{C}\left(\mathrm{OD}_{600}=0.4\right)$ before being harvested by centrifugation. The Ri plasmid was isolated with a Plasmid Mini AX Kit (A\&A Biotechnology, Poland). PCR amplification was carried out in a $25 \mu \mathrm{L}$ reaction volume containing $5 \mu \mathrm{L}$ DNA solution, $5 \mu \mathrm{L}$ of each primer (forward and reverse), $2.5 \mu \mathrm{L}$ of $10 \times$ TaqNova reaction buffer, $1.5 \mathrm{mM} \mathrm{MgCl} 2,0.2 \mathrm{mM}$ dNTP mix and $1.25 \mathrm{U}$ of TaqNova DNA polymerase (Blirt, Poland). Amplification conditions: 36 cycles, initial denaturation at $95{ }^{\circ} \mathrm{C}$ for $2.30 \mathrm{~min}$, denaturation at $95{ }^{\circ} \mathrm{C}$ for $0.30 \mathrm{~min}$, primer

Table 2 Comparison of morphology and biomass yield of transformed (HR-plants) and untransformed (SD-plants) plants of $R$. glutinosa after 12 months of growth in a greenhouse

\begin{tabular}{lrl}
\hline Morphology & \multicolumn{1}{l}{ HR-plants } & \multicolumn{1}{l}{ SD-plants } \\
\hline Number of leaves/plant & $16.08^{\mathrm{a}} \pm 0.89$ & $9.07^{\mathrm{b}} \pm 0.3$ \\
Length of leaf $(\mathrm{cm})$ & $6.17^{\mathrm{a}} \pm 0.16$ & $4.30^{\mathrm{b}} \pm 0.03$ \\
Width of leaf $(\mathrm{cm})$ & $1.25^{\mathrm{a}} \pm 0.08$ & $1.69^{\mathrm{b}} \pm 0.05$ \\
Number of lateral branches & $3.67^{\mathrm{a}} \pm 0.19$ & $1.78^{\mathrm{b}} \pm 0.15$ \\
Root biomass $(\mathrm{g} /$ plant $)$ & & \\
FW & $26.85^{\mathrm{a} *} \pm 0.55$ & $2.92^{\mathrm{b}} \pm 0.43$ \\
DW & $5.68^{\mathrm{a}} \pm 0.24$ & $0.67^{\mathrm{b}} \pm 0.04$ \\
Shoot biomass (g/plant) & & \\
FW & $5.38^{\mathrm{a}} \pm 0.74$ & $3.53^{\mathrm{b}} \pm 0.56$ \\
DW & $1.16^{\mathrm{a}} \pm 0.05$ & $0.77^{\mathrm{b}} \pm 0.03$ \\
\hline
\end{tabular}

* Values within a row followed with a different letter were significantly different from each other at $p \leq 0.05$ according to the MannWhitney U test using STATISTICA 10 (STATSoft) Software. Data are mean $\pm \mathrm{SE}$ of $20 \mathrm{HR}$ - and $20 \mathrm{SD}$-plants 
annealing at $55{ }^{\circ} \mathrm{C}$ for $0.30 \mathrm{~min}$, extension at $72{ }^{\circ} \mathrm{C}$ for $1.10 \mathrm{~min}$ and final extension for $3 \mathrm{~min}$ at $72{ }^{\circ} \mathrm{C}$. The PCR products were analyzed with a $100 \mathrm{bp}$ DNA ladder on $1.2 \%$ agarose gel (Bioline, UK) (for $1 \mathrm{~h}$ at a constant voltage of $90 \mathrm{~V}$ ) in TBE buffer. The gel was stained with ethidium bromide, visualized under UV light and photographed using DNR Bio-Imaging System MiniBIS Pro (Israel).

\section{$R N A$ isolation and reverse transcriptase (RT)-PCR analysis}

RNA was isolated from the same plant material described above (see: DNA extraction and PCR analysis) using a Total RNA Prep Plus Minicolumn Kit (A\&A Biotechnology, Poland) based on RNA isolation method developed according to the manufacturer's protocol. UV absorbance was used to determine the amount of RNA added to the cDNA reaction. PCRs were then set up using cDNA derived from the same amount of input RNA. The isolated RNA has an A260/280 ratio of 1.6-1.8. An enhanced Avian HS RT-PCR Kit, SIGMA was used to perform the $\mathrm{RT}$ reaction according to the manufacturer's protocol. The cDNA was used immediately or stored at $-20{ }^{\circ} \mathrm{C}$. The PCR reaction mixture used for PCR amplification consisted of a cDNA template, $0.5 \mu \mathrm{M}$ of each primer, $10 \times$ AccuTaq Buffer, 0.5 U of AccuTaq LA DNA Polymerase Mix, $0.2 \mathrm{mM}$ each dNTP and water to a final volume of $20 \mu \mathrm{L}$. A negative control was included in each experiment (a sample without a cDNA template). The primer sequences for the target $\operatorname{rol} \mathrm{A}, \mathrm{B}, \mathrm{C}$ genes and the ubiquitin reference gene (Blirt S.A. Gdańsk, Poland) were planned using Primer 3 software.

\section{Evaluation of iridoid and phenylethanoid glycoside contents}

Six sets of samples were taken for UHPLC analyses: the shoot cultures grown for 4 weeks on solid (in glass jars) and in liquid (sprinkle bioreactor) MS multiplication media, leaves and roots of HR-plants grown in the greenhouse for 6 and 12 months and leaves and roots of SDplants (seed-derived plants) grown in the greenhouse for 12 months. The plant materials were lyophilized and powdered. Iridoid and phenylethanoid extraction from plant materials as well as quantitative analysis was also performed on the leaves and roots of the SD-plants. The compounds were identified according to their retention times, UV spectra and ion mass spectra by comparison with authentic standards as described earlier (Piatczak et al. 2012, 2015). The distribution of iridoid and phenylethanoid glycosides according to plant material are presented in Table 3 as mean values \pm SE.

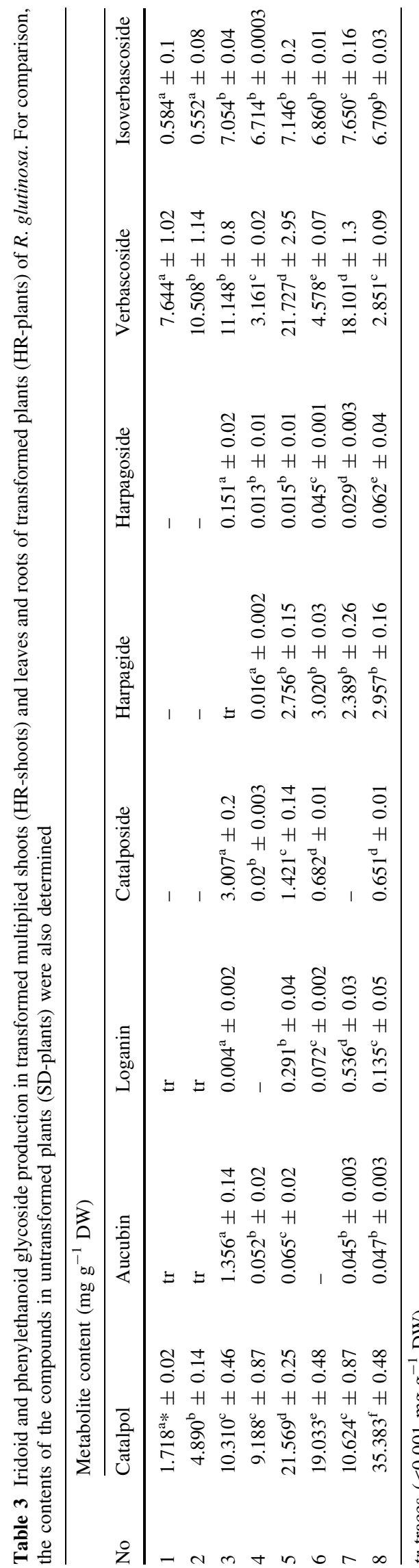

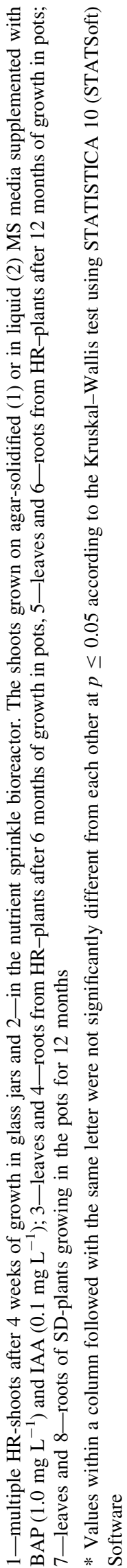




\section{Results}

Plant regeneration from hairy roots

The transformed roots of $R$. glutinosa (RS-2 line) established from shoot explants inoculated with the A4 strain of A. rhizogenes (Piątczak et al. 2012) showed spontaneous adventitious shoot formation, when grown in WPM liquid medium without growth regulators (Fig. 1a). The shoots about $1 \mathrm{~cm}$ long were excised from transformed roots and transferred on shoot multiplication medium (MS medium with $0.1 \mathrm{mg} \mathrm{L}^{-1}$ IAA and $1.0 \mathrm{mg} \mathrm{L}^{-1} \mathrm{BAP}$ ). The type and concentrations of plant growth regulators were chosen on the basis of our earlier experiments with untransformed $R$. glutinosa shoots (Piatczak et al. 2014). The HR-shoots were multiplied in two culture systems: $300 \mathrm{~mL}$ glass cap jars containing $50 \mathrm{~mL}$ of agar-solidified medium and a $5 \mathrm{~L}$ nutrient sprinkle bioreactor, in which liquid medium $(1 \mathrm{~L})$ was dispersed into droplets and sprayed into shoots. The results revealed that the transformed shoot culture in bioreactor was more efficient (Table 1). After 4 weeks an average $478 \pm 58.7$ shoots per bioreactor were obtained (Fig. 1b) giving a multiplication rate of 28, estimated as the average number of shoots per single explant. This value was 1.6 times higher than that of the shoots multiplied in the glass jars on solid medium (Fig. 1c) of the same
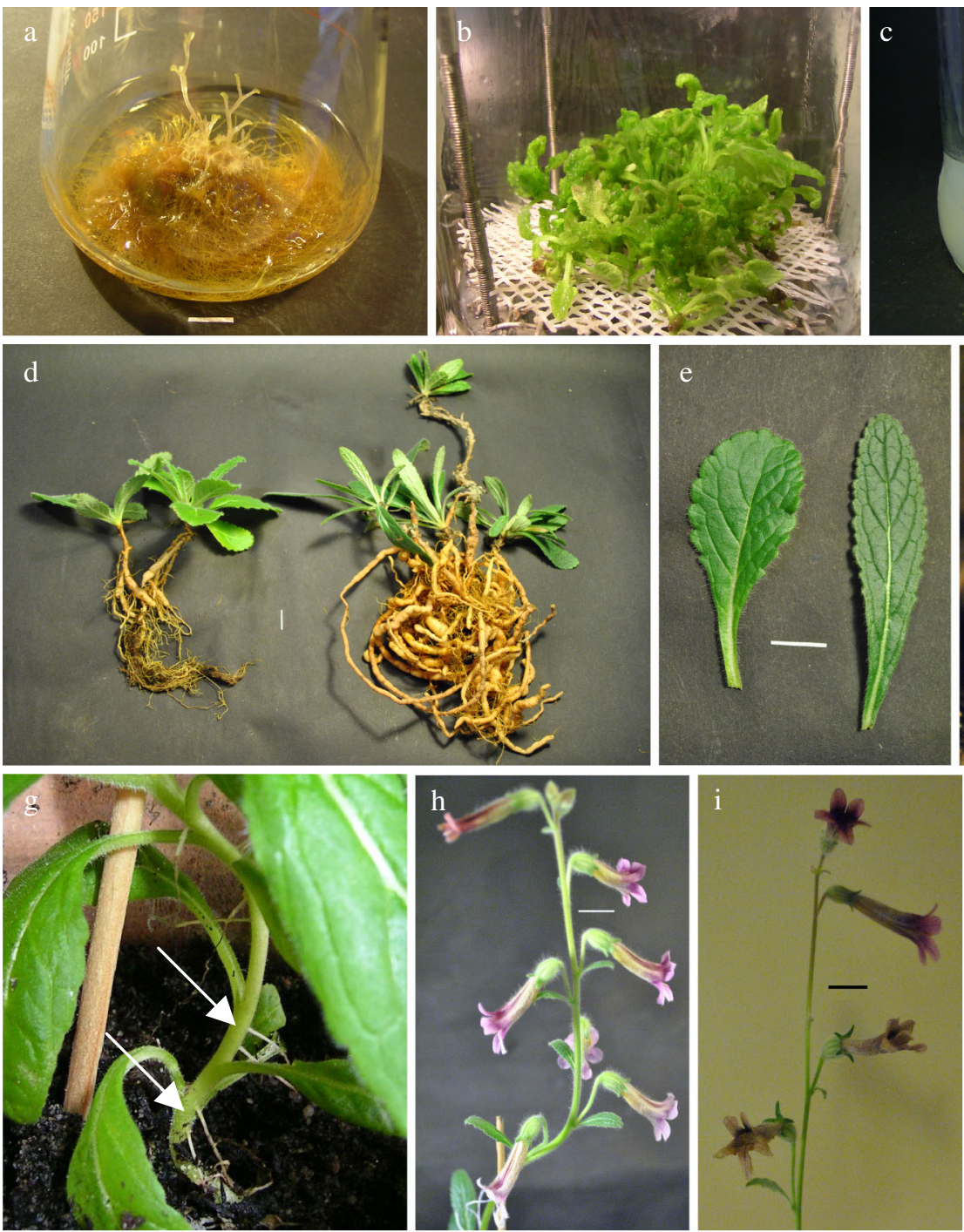

Fig. 1 Regeneration of $R$. glutinosa HR-plants; a spontaneous shoot regeneration from hairy roots after 4 weeks of growth in liquid WPM medium without growth regulators ( $3 \%$ sucrose); b, c transformed shoots multiplied for 4 weeks in a nutrient sprinkle bioreactor in liquid medium (b) and in a glass jar on solid MS medium (c) with BAP (1.0 $\left.\mathrm{mg} \mathrm{L}^{-1}\right)$ and IAA $\left(0.1 \mathrm{mg} \mathrm{L}^{-1}\right)$; d 12-month-old plants grown in the soil: left untransformed plant derived from seeds, right transformed plant regenerated from hairy roots; e leaves of SD-plant (left) and HR-plant (right); f numerous buds (arrows) formed from transformed shoot; $\mathbf{g}$ aerial roots (arrows) formed on transformed shoots; $\mathbf{h}$, i flowers of HR-plant (h) and SD-plant (i) after 4-6 months of growth in the pots. Bars $1 \mathrm{~cm}$ 
composition: 17 shoots per explant after 4 weeks of culture. HR-shoots grown in the bioreactor were also characterized by high biomass. A 234.7-fold increase in FW (70.4 g per bioreactor from an initial inoculum of $0.3 \mathrm{~g}$ ) and 361-fold increase in DW (6.5 g per bioreactor from an initial inoculum of $0.018 \mathrm{~g}$ ) was observed after 4 weeks of culture. These values are twice as high as those of the HRshoots cultured on solid medium in cap jars (Table 1). Four-week-old HR-shoots multiplied in the bioreactor were rooted on agar-solidified MS medium containing $0.1 \mathrm{mg} \mathrm{L}^{-1}$ IAA, $0.1 \mathrm{mg} \mathrm{L}^{-1}$ IBA or neither. The rooting frequency (100\% after 4 weeks of culture), number of roots per shoot (average 15) and length of roots (40-43 $\mathrm{mm}$ ) were greatest in the presence of auxin, with no significant difference observed between media containing IAA or IBA. The plantlets were acclimatized for 8 weeks and then maintained in the greenhouse for further growth. The survival rate of the acclimatized plants was $100 \%$.

The characteristics of transformed plants cultivated in the greenhouse

The phenotypical changes in HR-plants after a 12-month period of growth in the greenhouse were investigated. The typical phenotype known as hairy root syndrome, i.e. short internodes, stunted growth and wrinkled leaves of $R$. glutinosa plants regenerated from hairy roots, was not observed. However, transgenic plants exhibited some morphological alterations compared with untransformed control plants derived directly from seeds (SD-plants) (Table 2; Fig. 1d-h). HR-plants displayed a better developed root system with longer and higher numbers of branches. Roots were even produced on the aerial parts of the plants (Fig. 1g). The shoots of the HR-plants also demonstrated more lateral branching and were characterized by a higher average number of leaves. Differences in leaf size and shape were also observed (Table 2; Fig. 1e). These changes resulted in a significant increase of the total biomass of the HR-plants. The mean total biomass of 1-year-old HR-plants calculated as FW of shoots and roots was five times higher than that observed in untransformed plants of the same age $(32.2 \pm 1.1 \mathrm{~g}$ vs. $6.4 \pm 0.9 \mathrm{~g})$. These changes were mainly associated with the increase in root biomass. In the pRi-transformed regenerants of $R$. glutinosa, the proportion of root mass increased from $47 \%$ of whole plant mass for the untransformed plants to $83 \%$ for the transformants. The $R$. glutinosa plants regenerated from hairy roots flowered later than the SD-plants (after 6 months of greenhouse growth compared to 3-4 months), and the two types of plants demonstrated different average flower numbers (Fig. 1h, i).

\section{Confirmation of transformation}

To indicate the presence of T-DNA in the genome of the $R$. glutinosa plants regenerated from hairy roots, the genomic DNA was analysed by PCR analysis. The results showed that fragments of rolB (386 bp) and rolC (582 bp) genes were amplified in all analyzed transformed plants. No such amplification was found in the DNA isolated from untransformed plants used as a negative control. The expression of transgenes was further tested using RT-PCR. A 378 bp side band was observed with rolC gene specific primers in the shoots of transformed plants. Although RTPCR analysis did not reveal the presence of the amplified product of the rolB gene, PCR analysis confirmed the integration of the gene into the genome of $R$. glutinosa HRplants.

Iridoid and phenylethanoid glycosides in HR-shoot cultures

UHPLC was used to determine the several selected iridoid and phenylethanoid glycoside contents of HR-shoots of $R$. glutinosa cultured on multiplication media in the jars and the sprinkle bioreactor as well as in the leaves and roots of HR-plants. As shown in Table 3, only one iridoid glycoside (catalpol) and two phenylethanoid glycosides (verbascoside and isoverbascoside) were identified in detectable amounts in HR-shoots grown in both solid (jars) and liquid (bioreactor) MS media supplemented with $0.1 \mathrm{mg} \mathrm{L}^{-1}$ IAA and $1.0 \mathrm{mg} \mathrm{L}^{-1}$ BAP. The level of catalpol in HRshoots grown in the bioreactor was almost three-times higher (about $5 \mathrm{mg} \mathrm{g}^{-1} \mathrm{DW}$ ) than that of the HR-shoots proliferated in jars. A similar trend was observed in the case of verbascoside production, but smaller differences were observed between shoots grown in the two different culture systems $\left(10.5 \mathrm{mg} \mathrm{g}^{-1} \mathrm{DW}\right.$ in the bioreactor vs. $7.6 \mathrm{mg} \mathrm{g}^{-1} \mathrm{DW}$ in the jars). No differences were observed between the content of isoverbascoside in HR-shoots proliferated in bioreactor and those in jars (Table 3).

Iridoids and phenylethanoids in transformed plants

After 6 or 12 months of growth in the greenhouse, HRshoot derived plants of $R$. glutinosa demonstrated significantly elevated production of catalpol, verbascoside and isoverbascoside as compared to HR-shoots multiplied in the bioreactor or jars (Table 3). Additionally, five other iridoids (aucubin, loganin, catalposide, harpagoside and harpagide) were found to have accumulated in whole plants. The results given in Table 3 show that in all analyzed extracts, catalpol was the dominant compound. Older HR-plants (12-month-old) contain higher amounts of catalpol, loganin, harpagide and verbascoside than the 
younger HR-plants (6-month-old) (Table 3). For example, twice as much catalpol and verbascoside was found in the leaves of 12-month-old HR-plants than those of 6-monthold HR-plants (Table 3). However, more catalposide, aucubin and harpagoside were identified in the leaves of the younger plants.

Comparison of pRi-transformed regenerants to untransformed plants in phenylethanoid and iridoid production

The results of the present study demonstrate that catalpol was sequestered to a greater degree in the leaves of 12-month-old HR-plants than the leaves of SD-plants $\left(21.6 \mathrm{mg} \mathrm{g}^{-1} \mathrm{DW}\right.$ vs. $10.6 \mathrm{mg} \mathrm{g}^{-1} \mathrm{DW}$ ), but it was found in smaller amounts in the roots of transformed plants than in those of SD-plants $\left(19.0 \mathrm{mg} \mathrm{g}^{-1} \mathrm{DW}\right.$ vs. $\left.35.4 \mathrm{mg} \mathrm{g}^{-1} \mathrm{DW}\right)$. A. rhizogenesmediated transformation significantly increased the accumulation of catalposide (the 6-O-ester of catalpol). Greater levels of catalposide were found in the leaves of 6-month-old HR-plants than those of 12-month-old HR-plants (3.0 $\mathrm{mg} \mathrm{g}^{-1} \mathrm{DW}$ vs. $1.4 \mathrm{mg} \mathrm{g}^{-1} \mathrm{DW}$ ). However, in SDplants, catalposide was only found to be present in the roots, where its levels were similar to those observed in the roots of 12-month-old HR-plants-about $0.7 \mathrm{mg} \mathrm{g}^{-1} \mathrm{DW}$; none was detected in the aerial parts of SD-plants (Table 3). Previous findings indicated that catalposide is the main iridoid in hairy roots of $R$. glutinosa, from which the HR-plants were derived (Piątczak et al. 2012).

Harpagoside is generally present in plants of the Orobanchaceae, Scrophulariaceae and Lamiaceae families together with harpagide as was revealed also in the present study. No significant differences were observed between the HR- and SD-plants of $R$. glutinosa with regard to their mean harpagoside and harpagide contents, when the plants of the same age were compared. The levels of harpagide ranged from $2.4 \mathrm{mg} \mathrm{g}^{-1}$ DW (leaves of SD-plants) to $3.0 \mathrm{mg} \mathrm{g}^{-1} \mathrm{DW}$ (roots of HR-plants). The levels of harpagoside were observed to be much lower, and varied between $0.015 \mathrm{mg} \mathrm{g}^{-1} \mathrm{DW}$ (leaves of HR-plants) to $0.062 \mathrm{mg} \mathrm{g}^{-1}$ DW in roots of SD-plants (Table 3).

Besides iridoids, the leaves and roots of $R$. glutinosa HR-plants and SD-plants were able to produce two phenylethanoid glycosides: verbascoside and isoverbascoside. Verbascoside content was found to be greater in the leaves of HR-plants than those of SD-plants $\left(21.7 \mathrm{mg} \mathrm{g}^{-1} \mathrm{DW}\right.$ vs. $18.1 \mathrm{mg} \mathrm{g}^{-1}$ DW). Similarly, the roots of HR-plants accumulated more verbascoside than the roots of SD-plants ( $4.6 \mathrm{mg} \mathrm{g}^{-1}$ DW vs. $2.9 \mathrm{mg} \mathrm{g}^{-1} \mathrm{DW}$ ). Little difference in isoverbascoside content was observed between the leaves and roots of transformed and untransformed plants of $R$. glutinosa, and between the older and younger HR-plants (Table 3).

\section{Discussion}

Previous studies by Hwang (2005) and Zhou et al. (2009) have demonstrated the regeneration of $R$. glutinosa shoots from A. rhizogenes ATCC 15834 mediated hairy roots via the callus stage in the presence of cytokinin. On the other hand, in our study, an addition of any plant growth regulators nor changing the culture conditions were not necessary for obtaining shoot regeneration from hairy roots. Spontaneous regeneration of shoots from hairy root cultures has been also reported earlier for, inter alia T. indica (Chaudhuri et al. 2006), Centaurium erythraea (Piatczak and Wysokinska 2006), P. indica (Gangopadhyay et al. 2010), Ophiorrhiza rugosa (Kamble et al. 2011) and Rauwolfia serpentina (Mehrotra et al. 2013). According to Mehrotra et al. (2013) the depletion of nutrient contents during continuous growth and changes in levels or sensitivity to phytohormones in transformed tissues can be considered as factors responsible for the spontaneous regeneration of shoots.

The HR-shoots of $R$. glutinosa were successfully proliferated in the sprinkle bioreactor as it was shown in Fig. $1 \mathrm{~b}$ and in Table 1 giving the high multiplication rate (28). The sprinkle bioreactor has previously been used for untransformed $R$. glutinosa shoot proliferation, but the multiplication rate (21 shoots per explant after 4 weeks of culture) was slightly lower than that achieved for HR-shoots (Piatczak et al. 2014). The survival rate of the pRi- transformed $R$. glutinosa plants after the acclimatization period in the pots was $100 \%$ : similar or even higher than that reported earlier by Piatczak et al. (2014) for untransformed plants of R. glutinosa (86-93\%). Several differences were observed in the morphology and biomass of SD- and HR- $R$. glutinosa plants, most notably, a considerable increase in root biomass of the HR-plants. This is one of the most commonly observed properties of pRi-transformed regenerants, which was found also in such transgenic plants as Catharanthus roseus (Choi et al. 2004), T. indica (Chaudhuri et al. 2006), Aralia elata (Kang et al. 2006) and $P$. indica (Gangopadhyay et al. 2010). The increase is due to the influence of the introduced rol genes on hormonal synthesis and sensitivity. Casanova et al. (2003) have reported that the rolC gene exhibits both cytokinin-like and auxin-like activity, resulting in the better rooting ability observed in Dianthus caryophyllus transformed plants. It has been reported that the expression of $\mathrm{rol}$ genes in transgenic plants can affect not only the phenotype of the plants but also the accumulation of secondary metabolites (Grishchenko et al. 2013). Transgenic R. glutinosa plants appear to be good producers of iridoids and phenylethanoids. Although Hwang (2005) has already reported the presence of catalpol in $R$. glutinosa plants regenerated from hairy roots transformed by A. rhizogenes strain ATCC 
15834 , its content was nearly four times lower $(0.56 \%$ DW) than that reported in our study. The yields (content in mg per gram DW $\times$ DW grams per plant) of the iridoid and other analyzed compounds can be further improved in transgenic $R$. glutinosa plants since the total fresh and dry weights of shoots and roots were higher than those of the untransformed plants. Hence, the yield of catalpol was about $415 \%$ greater in HR-plants (133 mg per plant) than in SD-plants (32 mg/plant), while catalposide and verbascoside were 1,255 and $323 \%$ greater, respectively. This suggests that the effect of the rolC gene on iridoid and phenylethanoid glycoside production is mainly a consequence of increased stimulation of biomass, not a direct effect of the biosynthetic capacity of $R$. glutinosa transgenic plants. A similar result was reported by Palazon et al. (1998) in alkaloid production in tobacco cultures.

In conclusion, transgenic plants were successfully created from hairy roots of $R$. glutinosa and a number of iridoid (catalpol, aucubin, loganin, catalposide, harpagide, harpagoside) and phenylethanoid (verbascoside and isoverbascoside) glycosides were detected in them. The ability of pRi-transformed regenerants to biosynthesize these metabolites and the superiority of the plants over untransformed plants in terms of shoot and root biomass suggest that induction of transgenic plants from hairy roots may be valuable strategy to achieve a higher yield of bioactive compounds in $R$. glutinosa. This study is the first to describe the production of secondary metabolites other than catalpol in $R$. glutinosa plants induced by transformation with A. rhizogenes strain A4.

Open Access This article is distributed under the terms of the Creative Commons Attribution 4.0 International License (http://creative commons.org/licenses/by/4.0/), which permits unrestricted use, distribution, and reproduction in any medium, provided you give appropriate credit to the original author(s) and the source, provide a link to the Creative Commons license, and indicate if changes were made.

\section{References}

Angiosperm Phylogeny Group (2009) An update of the Angiosperm Phylogeny Group classification for the orders and families of flowering plants: APG III. Bot J Linn Soc 161:105-121

Bercetche J, Chriqui D, Adam S, David C (1987) Morphogenetic and cellular reorientation induced by Agrobacterium rhizogenes (strains 1855, 2659 and 8196) on carrot, pea and tobacco. Plant Sci 52:195-210

Casanova E, Zuker A, Trillas MI, Moysset L, Vainstein A (2003) The rolC gene in carnation exhibits cytokinin and auxin-like activities. Sci Hort 97:321-333

Chaudhuri KN, Ghosh B, Tepfer D, Jha S (2006) Spontaneous plant regeneration in transformed roots and calli from Tylophora indica: changes in morphological phenotype and tylophorine accumulation associated with transformation. Plant Cell Rep 25:1059-1066

Choi PS, Kim YD, Choi KM, Chung HJ, Choi DW, Liu JR (2004) Plant regeneration from hairy-root cultures transformed by infection with Agrobacterium rhizogenes in Catharanthus roseus. Plant Cell Rep 22:828-831. doi:10.1007/s00299-004-0765-3

Christey M (2001) Use of Ri-mediated transformation for production of transgenic plants. In Vitro Cell Dev Biol Plant 37:687-700. doi:10.1079/IVP2001203

Gangopadhyay M, Chakraborty D, Bhattacharyya S, Bhattacharya S (2010) Regeneration of transformed plants from hairy roots of Plumbago indica. Plant Cell Tiss Organ Cult 102:109-114. doi:10.1007/s11240-010-9702-z

Giri A, Narasu ML (2000) Transgenic hairy roots: recent trends and applications. Biotechnol Adv 18:1-22

Grishchenko OV, Kiselev KV, Tchernoded GK, Fedoreyev SA, Veselova MV, Bulgakov VP, Zhuravlev YN (2013) The influence of the rolC gene on isoflavonoid production in callus cultures of Maackia amurensis. Plant Cell Tiss Organ Cult 113:429-435. doi:10.1007/s11240-012-0283-x

Hwang SJ (2005) Growth characteristics and catalpol production in chinese foxglove (Rehmannia glutinosa Liboschitz) hairy roots transformed with Agrobacterium rhizogenes ATCC15834. J Plant Biol 48:380-386 (in Korean)

Kamble S, Gopalakrishnan R, Eapen S (2011) Production of camptothecin by hairy roots and regenerated transformed shoots of Ophiorrhiza rugosa var. decumbens. Nat Prod Res 25:1762-1765. doi:10.1080/14786419.2011.559469

Kang HJ, Anbazhagan VR, You XL, Moon HK, Yi JS, Choi YE (2006) Production of transgenic Aralia elata regenerated from Agrobacterium rhizogenes-mediated transformed roots. Plant Cell Tiss Org Cult 85:187-196. doi:10.1007/s11240-005-9070-2

Kitagawa I, Fukuda Y, Taniyama T, Yoshikawa M (1991) Chemical studies on crude drug processing. VII. On the constituents of Rehmanniae radix. (1): absolute stereostructures of rehmaglutins A, $\mathrm{B}$ and D isolated from Chinese Rehmanniae Radix, the dried root of Rehmannia glutinosa Libosch. Chem Pharm Bull 39:1171-1176

Mehrotra S, Goel MK, Rahman LU, Kukreja AK (2013) Molecular and chemical characterization of plants regenerated from Rimediated hairy root cultures of Rauwolfia serpentina. Plant Cell Tiss Organ Cult 114:31-38. doi:10.1007/s11240-013-0302-6

Murashige T, Skoog F (1962) A revised medium for rapid growth and bioassay with tobacco culture. Physiol Plant 15:473-497

Palazon J, Cusido RM, Roig C, Pinol MT (1998) Expression of the rolC gene and nicotine production in transgenic roots and their regenerated plants. Plant Cell Rep 17:384-390

Piątczak E, Królicka A, Wysokińska H (2006) Genetic transformation of Centaurium erythraea Rafn by Agrobacterium rhizogenes and the production of secoiridoids. Plant Cell Rep 25:1308-1315. doi:10.1007/s00299-006-0155-0

Piątczak E, Królicka A, Wielanek M, Wysokińska H (2012) Hairy root cultures of Rehmannia glutinosa and production of iridoid and phenylethanoid glycosides. Acta Physiol Plant 34:22152224. doi:10.1007/s11738-012-1022-y

Piątczak E, Grzegorczyk-Karolak I, Wysokińska H (2014) Micropropagation of Rehmannia glutinosa Libosch.: production of phenolics and flavonoids and evaluation of antioxidant activity. Acta Physiol Plant 36:1693-1702. doi:10.1007/s11738-014-1544-6

Piątczak E, Kuźma Ł, Sitarek P, Wysokińska H (2015) Shoot organogenesis, molecular analysis and secondary metabolite production of micropropagated Rehmannia glutinosa Libosch. Plant Cell Tiss Org Cult 120:539-549. doi:10.1007/s11240-014-0620-3

Zhang RX, Li MX, Jia ZP (2008) Rehmannia glutinosa: review of botany, chemistry and pharmacology. J Ethnopharmacol 117:199-214. doi:10.1016/j.jep.2008.02.018

Zhou YQ, Duan HY, Zhou CE, Li JJ, Gu FP, Wang F, Hang ZY, Gao ZM (2009) Hairy root induction and plant regeneration of Rehmannia glutinosa Libosch. f. hueichingensis Hsiao via Agrobacterium rhizogenes-mediated transformation. Russ J Plant Physiol 56:224-231 